\title{
WHAT DOES GRAMMAR TELL US ABOUT ACTION? ${ }^{* 1}$
}

\author{
Elizabeth Couper-Kuhlen
}

\begin{abstract}
Using cases of misalignment and realignment in the unfolding of interactional sequences in which future actions and events are being negotiated in everyday English conversation, this paper demonstrates that participants distinguish between the initiating actions of Proposal*, Offer*, Request*, and Suggestion*, if these labels are understood as technical terms for distinct constellations of answers to the questions (i) who will carry out the future action? and (ii) who will benefit from it?. The argument made is that these different action types are routinely associated with different sets of recurrent linguistic forms, or social action formats, and that it is through these that speakers can frame their turns as implementing one action type as opposed to another and that recipients can recognize these actions as such and respond to them accordingly. The fact that there is only a limited amount of 'polysemy', or overlap in the formats commonly used for Proposals*, Requests*, Offers*, and Suggestions* in English conversation, means that these formats deliver often distinctive cues to the type of action being implemented. When misalignments and realignments occur, they can often be traced to the fact that 'polysemous' linguistic formats have been used to implement the initiating action.
\end{abstract}

Keywords: Action formation; Action recognition; Social action format; Directive; Request; Offer; Proposal; Suggestion.

\section{Introduction}

Although the title of this article may appear to presuppose that grammar has at least something to do with action, this assumption has actually been called into question by many a conversation analyst, foremost among them Schegloff, who writes "sequential features of conversation ... overshadow the contribution made by its linguistic form to what an utterance is doing" (1984: 36) and, more pointedly, "it will not do, for a variety of reasons, to use features of linguistic form as sole, or even invariant though not

*Elizabeth Couper-Kuhlen acknowledges funding from the Finland Distinguished Professor project Grammar and Interaction (Academy of Finland) during the preparation of this article.

${ }^{1}$ This paper is a revised version of a lecture given at the LAGB meeting in Leeds (September, 2010) and a paper delivered at the symposium Grammar and interaction revisited in Helsinki (March 2011). I am grateful to Steve Levinson, John Heritage, and to discussants at the Helsinki symposium, in particular to Marja Etelämäki, for help in thinking through the issues involved here. 
exhaustive, indicators or embodiments of (conversational) objects", the latter term referring to social actions (1984: 49f). To linguists, such statements amount to throwing down the gauntlet and the present study is one linguist's attempt to take up the challenge. I will argue that on the contrary, the linguistic format of an initiating turn in conversation provides what are often distinctive cues to the social action it is implementing. When the linguistic formats for initiating actions are conflicting or ambivalent, this can lead to misalignments between speaker and recipient; realignments in responsive actions may then become necessary. The conversational evidence examined here thus suggests that linguistic forms can be thought of as social action formats (Fox 2000, 2007), recurrent and sedimented ways of accomplishing specific social actions in talk-in-interaction.

The focus of this study is on an extended family of initiating actions in conversation that involve the speaker attempting to bring about some future action, event or situation (see e.g. Ervin-Tripp 1976; Searle 1976). These actions have in common that, as Searle has put it, they aim at 'getting the world to match the words' (Searle 1976). Searle's illocutionary classification provides for two distinct classes of such actions: Directives, including requests, proposals and suggestions, and Commissives, including offers and invitations. In this study the two categories will be treated as belonging to one single extended family of action, for reasons to be explained below. For the time being, suffice it to observe that - at least in English - all of these directive-commissive actions can be implemented by imperatives, e.g. Bring some chairs, Let's do that, Put some ointment on it, Have some more tea, Come on over.

Further features that members of this extended family have in common include: ${ }^{2}$

(i) The action or event which the speaker is attempting to bring about is something in the future, be it temporally immediate and intrinsic to the speech-event situation, or temporally remote and at a remove from the speech-event situation (Lindström frthc. ).

(ii) Issues of deontic status and stance are inherent in such actions (Stevanovic \& Peräkylä 2012). What is relevant is how strong a participant's rights are to decide what the world will be like in the future and/or how strong a participant's commitment is to bring about a particular future state of affairs.

(iii) The technically preferred way to respond to such actions (in a conversation-analytic sense) is by accepting, acquiescing or complying, i.e. agreeing and/or committing to carry out the future action, engage in the future activity or bring about the future situation. It therefore comes as no surprise that, at least in English, the same particle, e.g. okay or alright, can serve as a compliance marker to all such actions: Bring some chairs-Okay; Let's do that-Okay; Put some ointment on it - Okay; Have some more tea-Okay; Come on over-Okay.

\section{Realignment and misalignment in responses to directive-commissive actions}

Yet although a similar linguistic form can be used to implement these initiating actions and the same particle can serve to signal compliance with them, participants in mundane interaction actually make clear distinctions within the extended family of directivecommissive actions. This becomes obvious if we consider the way participants micromanage sequences built around them. At least two different issues appear to require

2 Some of these features are reminiscent of the felicity conditions for speech acts proposed by Austin 1962 and Searle 1969. Others, however, go well beyond what a speech act framework can provide. 
handling: (1) who will bear the costs and to whom the benefits will accrue; (2) who will execute the action being planned.

\subsection{Whose cost, whose benefit?}

A first piece of evidence that participants make distinctions within the directivecommissive family will be found in recipient behavior. On occasion, recipients treat their initial response to a directive-commissive action as inadequate and initiate selfrepair on it. For instance: ${ }^{3}$ (the turn implementing a directive-commissive action is bolded)

\section{(1) Buy you a drink (HG II-17)}

[It is Hyla's birthday and she and her girlfriend Nancy are going to the theater in the evening. Now they are making arrangements for the evening on the telephone.]

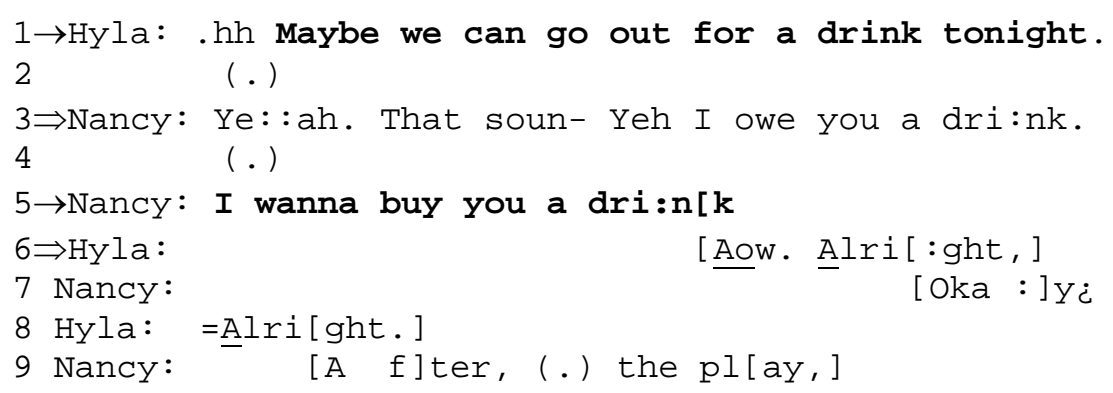

In line 1 Hyla launches the idea of going out for a drink that evening with Nancy. In line 3 Nancy starts her response by appearing to accept and deliver a positive evaluation of this idea: Yeah. That soun(ds good/like fun). However, she then breaks her turn off midway, aborting its action and opting for another, namely to announce that she owes Hyla a drink (line 3) and wants to take over the cost of Hyla's drink herself (line 5). This temporarily reverses the participant roles, in that it is now Nancy who is initiating a directive-commissive action with I wanna buy you a drink in line 5. In line 6 Hyla subsequently receipts Nancy's account in line 3 with Aow and acquiesces to the deontic implications of her turn in line 5 with Alright. The fact that Nancy repairs her response (line 3) suggests that she has an investment in establishing who will buy the drinks. Had she not repaired her turn, she would have gone on record as agreeing to share the cost of the drinks with Hyla that evening. ${ }^{4}$ Hyla's response to Nancy's revised action in line 6 puts her on record as agreeing to let Nancy pay for the drinks.

The recipient's repair, or realignment, of a responsive action in mid-course as well as socio-cultural understandings of what response tokens such as yeah or alright commit their speakers to in different sequential environments point here to at least two

\footnotetext{
${ }^{3}$ Fragments have been transcribed according to the Jeffersonian system: See e.g. Atkinson \& Heritage (1984: ix-Xvi).

4 Some readers may be inclined interpret Hyla's turn in line 1 as an invitation, with the implication that she will take over the costs. However, in the context of this phone call, where it is clear that Hyla and Nancy are going to the theater together to celebrate Hyla's birthday, line 1 does not come off as an invitation nor is it treated as one. Nancy's immediate response is not an expression of gratitude but instead appears to be evaluating the plan as a course of joint action (see also Stevanovic 2012).
} 
different sub-types of directive-commissive action. Hyla and Nancy in (1) appear to be orienting to the distinction between an action type involving sharing the costs and benefits of a future event equally, as opposed to an action type involving one of the participants bearing the cost and the other enjoying the benefit of the future event. ${ }^{5}$

There is also evidence for this distinction based on initiating speakers' behavior. For instance, we find occasions when the initiator of a directive-commissive action treats the recipient's response as inadequate and subsequently clarifies the original action and/or pursues a more adequate response to it in ensuing talk:

\section{(2) Coco’s-2 (nb017-2)}

[Edna has called her friend Margy to thank her for the luncheon she recently hosted where Edna was a guest. Edna now launches the idea of going to a restaurant called Coco's with Margy and Margy's mother.]

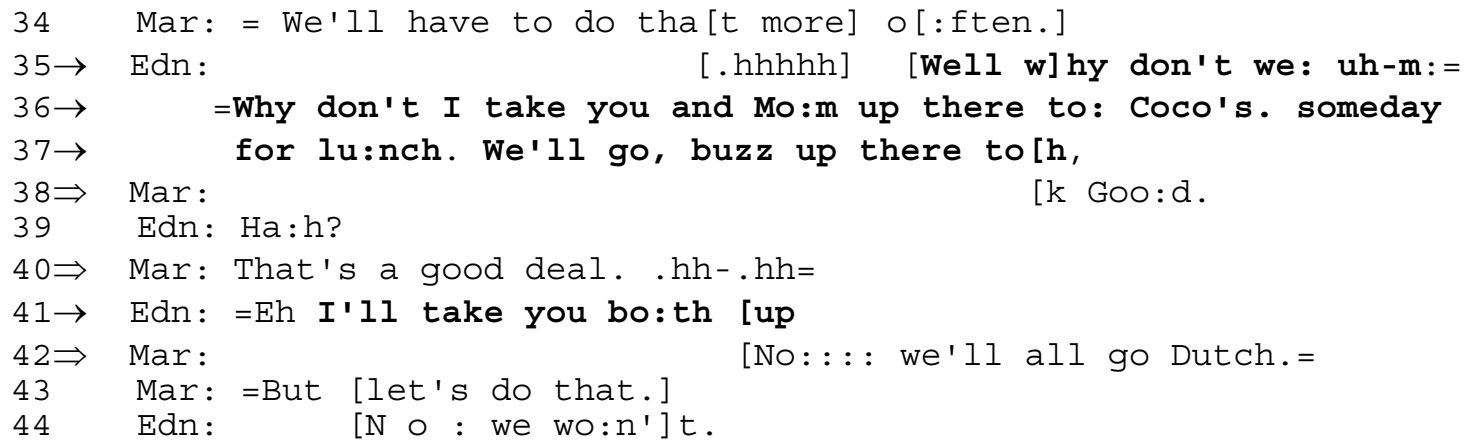

In lines 35-37 Emma lays out a tentative plan to take Margy and her mother to Coco's one day for lunch. Margy immediately evaluates this idea positively and appears to accept it: See line 38 Good and line 40 That's a good deal. But in reaction to this response Edna now redoes her turn as a plan to take Margy and her mother up (line 41). Now since Margy knows that Edna does not drive, Margy interprets this turn, or what she hears of it (I'll take you both), as meaning that Edna intends to pay the bill. This part of the plan Margy now adamantly rejects, insisting that they share the costs (line 42: No we'll all go Dutch). Edna rejects this, however (line 44: no we won't), while in an overlapping turn Margy commits to the overall project (line 43: but let's do that).

Here, although the recipient has indicated preliminary agreement with the plan being put forward (lines 38,40), the initiating speaker presents a revised version of it (line 41) and through this revision can be heard to 'pursue' a more adequate response from the recipient. In this case, the participants appear to agree that they both want the future event to take place but they disagree on the terms: Will Edna 'host' Margy and her mother, or will they share the costs? The same issue as in (1) concerning costs and benefits arises here, although rather than there being agreement among the participants, in (2) the respective allocation of costs serves as a basis of dispute.

\subsection{Whose agentivity?}

5 This initial determination of sub-types within the directive-commissive family was made in the spirit of Schegloff 1984, that is based on sequential features and not on linguistic forms. As will later emerge, however, linguistic forms can be shown to play a considerable role in cueing which directivecommissive action is being implemented. 
It is not only the distribution of costs and benefits with respect to a future planned activity that requires management. Whether both of the participants or only one of them is to carry out the future action in question can also be the basis of misunderstanding and require negotiation. This is apparent from the following fragment:

\section{(3) Greyhound bus (nb024-9)}

[Lottie and Emma are discussing how to handle Emma's Thanksgiving dinner, since Emma's husband is no longer available to take their daughter Barbara back to Los Angeles and Emma does not drive. Hugh is Barbara's husband. Several minutes earlier, Lottie has volunteered to drive Barbara back to Los Angeles but Emma has adamantly refused (see Ex. 5 below).]

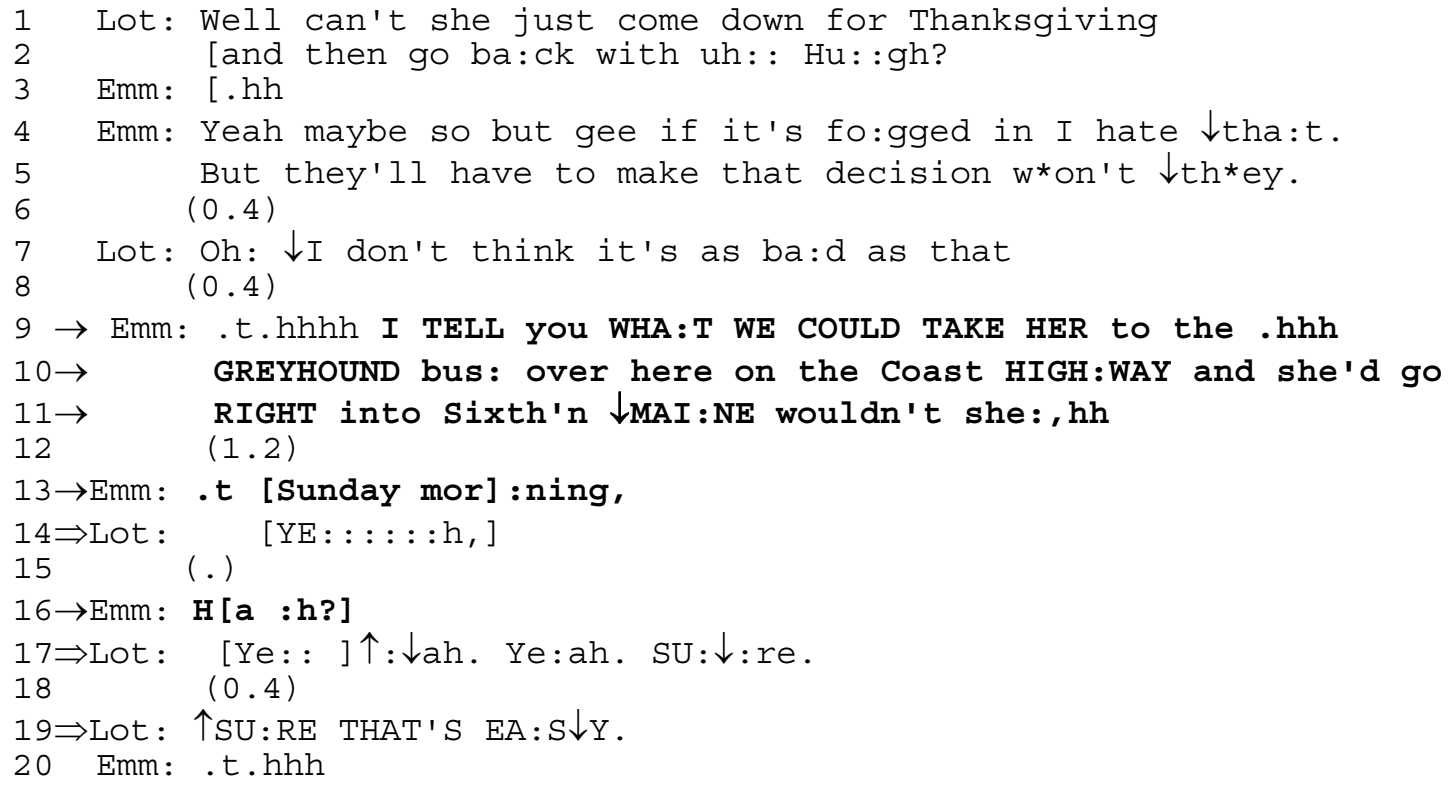

In lines 9-11 Emma advances the idea that they could take Barbara by car to the Greyhound bus stop, from where she could catch the bus home. When there is no immediate uptake on this plan from Lottie (line 12), Emma incrementally adds a temporal specification: Sunday morning (line 13). This overlaps with a relatively noncommittal acknowledgement token from Lottie ye:::ah (line 14). Lottie's response acknowledges Emma's prior turn as an assertion; it does not imply that Lottie will have any part in the event. But Emma is clearly expecting something different and pursues a more adequate response with Ha:h? (line 16). She does not treat the sequence as closed until Lottie agrees with Su:re (line 17) and then evaluates the plan with a more enthusiastic Su:re that's ea:sy (line 19). Lottie's responses now betoken commitment: They display an achieved understanding that she will have an active part in the plan, retrospectively ratifying Emma's we in line 9 as including her.

In this instance, both the initiating speaker's pursuit of an adequate response to her action and the realignment of her interlocutor's response provide evidence of another distinctive dimension with respect to directive-commissive actions: Namely, who will carry out the future action or activity being advocated? Lottie's initial response yeah treats Edna's prior turn as a descriptive statement of the way the world might be, but not as one that has deontic implications for her own behavior. By contrast, Lottie's 
subsequent responses sure and that's easy betoken an understanding that she will be involved as an agent in the future event. ${ }^{6}$

\subsection{Towards a taxonomy of directive-commissive actions}

\subsubsection{Proposals* and Offers*}

Situations such as the ones shown in (1)-(3) reveal that participants distinguish different kinds of directive-commissive action and that responses to them are shaped accordingly. More specifically, they show that participants differentiate actions to be undertaken jointly with shared costs and benefits from actions that are undertaken unilaterally with costs accruing to the initiator but benefits accruing to the recipient. This distinction can be schematized as follows, with Proposal* and Offer* serving as labels for the two categories: ${ }^{7}$

\begin{tabular}{|l|l|l|}
\hline & Agent of future action & Beneficiary of future action \\
\hline Proposal* & Self \& Other & Self \& Other \\
\hline Offer* $^{*}$ & Self & Other \\
\hline
\end{tabular}

Table 1. Distinctive dimensions of Proposals* and Offers*

In examples (1)-(3) we have seen participants working to achieve a common understanding of whether what is being advocated is a Proposal* or an Offer*. Other instances demonstrate that an intersubjective understanding of which action type is being implemented can be clear and undisputed from the outset:

\section{(4) Get together (Geri \& Shirley 12)}

[Shirley has been asking her friend Geri about what plans she has for seeing her out-of-town boyfriend again. Geri has explained that she may not see him until Thanksgiving or perhaps even Christmas.]

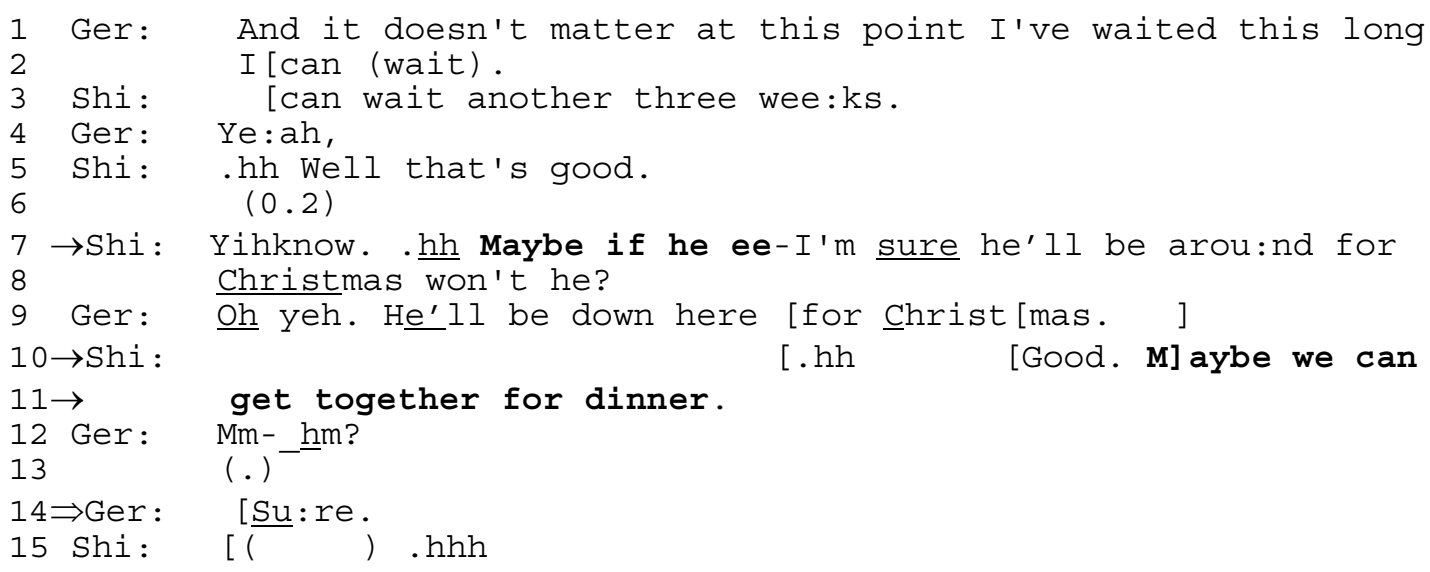

\footnotetext{
6 Based on Lottie's ultimate orientation to Emma's idea as something to be evaluated (see her that's easy in line 19), she appears to be treating the prior turn as a Proposal* for joint action.

7 The asterisk is intended to serve as a mnemonic reminder of the fact that these are technical, not lay terms.
} 
In line 7 Shirley launches a turn possibly already aimed at promoting a get-together with Geri and her boyfriend. However, she breaks this off prematurely in favor of ascertaining that Geri's boyfriend will indeed be around at Christmas: I'm sure he'll be around for Christmas won't he? (lines 7-8). This turn serves as a preliminary or 'pre' (Schegloff 1980, 2007): It allows Shirley to establish whether the conditions are right for advancing the idea that the three of them might get together. ${ }^{8}$ When Geri gives a goahead in line 9, Shirley proceeds with her initiative: Maybe we can get together for dinner (lines 10-11). Here the verb get together, in contrast to e.g. 'maybe I can take you', is suggestive of bilateral or joint action. Together with maybe, indexing the tentative nature of her plan, this conveys that Shirley is implementing a Proposal* and not an Offer*. Geri indicates that she takes it this way by first acknowledging the possibility (line 12) and then agreeing to it with Sure (line 14). Her response confirms commitment to participate as an active agent (cf. Lottie's Sure in (3) above). It does not imply simple acceptance of an Offer* as did Hyla's Alright in (1) above.

If Shirley's maybe we can get together for dinner in (4) conveys an unproblematic Proposal*, the following fragment exemplifies an unproblematic Offer* (see also Curl 2006):

\section{(5) Take her in Sunday (nb024-2)}

[Emma has announced to her sister Lottie that her husband walked out on her the night before. She is now worried about the upcoming Thanksgiving dinner she is planning to have for her daughter Barbara.]

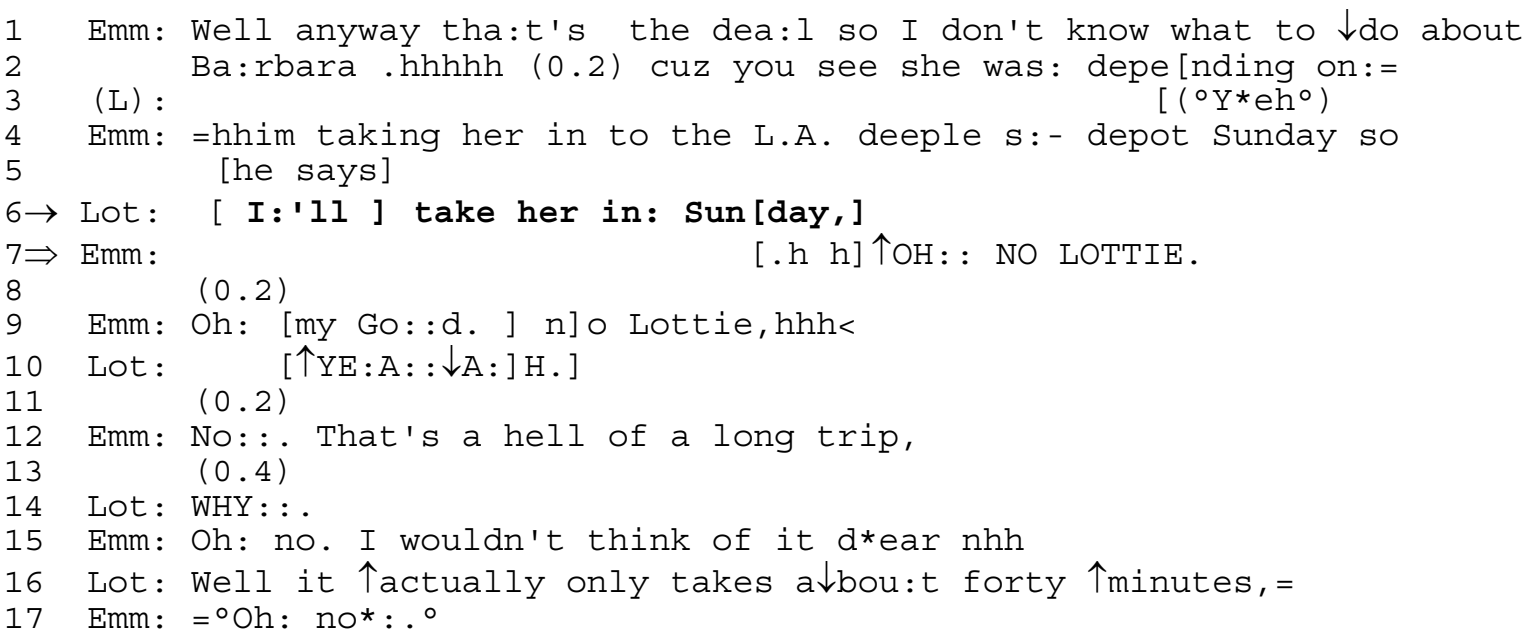

Lottie's turn I'll take her in Sunday (line 6) is not framed in terms of a bilateral or joint action that she and Emma could carry out together but rather as something Lottie will undertake herself for the benefit of Emma. Observe that Emma has earlier expressed a concern with I don't know what to do about Barbara (lines 1-2). This suggests that I'll take her in Sunday is a solution to a problem and therefore an Offer*, not a Proposal*. Emma's response is a prototypical one for an Offer*, in that she reacts immediately with determination to reject it. This is reminiscent of Margy's response to Edna's

${ }^{8}$ As Levinson (1983, fthc.) points out, what are called 'pre's' in Conversation Analysis are often attempts to establish whether the felicity conditions for an upcoming speech act, or projected action, hold. 
Offer* in (2) above: no we'll all go Dutch (line 42). In fact, in contrast to Proposals*, which are prototypically accepted (often with positive evaluation and enthusiasm), Offers* are prototypically rejected - or if accepted, then only reluctantly. ${ }^{9}$ This is further evidence of their distinctiveness with respect to the social order. Offers* are other-directed and hierarchical; the person accepting an offer acknowledges a need and puts him-/herself in the debt of the offerer. Proposals*, by contrast, are more symmetric and egalitarian in advocating joint action.

\subsubsection{Requests* and Suggestions*}

The directive-commissive examples considered so far have turned on the question of whether the costs and benefits of the planned activity will be shared or not and on the question of whether one or both participants will be active agents in it. However, there is conversational evidence to indicate that participants are sensitive to further distinctions among directive-commissive actions. For instance, they appear to treat an Offer*, in the definition above, as different from a type of action advocating something the recipient will do that will benefit the speaker, to be called here Request*. This is evident from the following case of response misalignment:

(6) Beauty parlor (nb028-20:30)

[Emma, who has recently separated from her husband, has spent the weekend alone. Her sister Lottie has just returned from an out-of-town trip and is now calling to find out how Emma got along in her absence.]

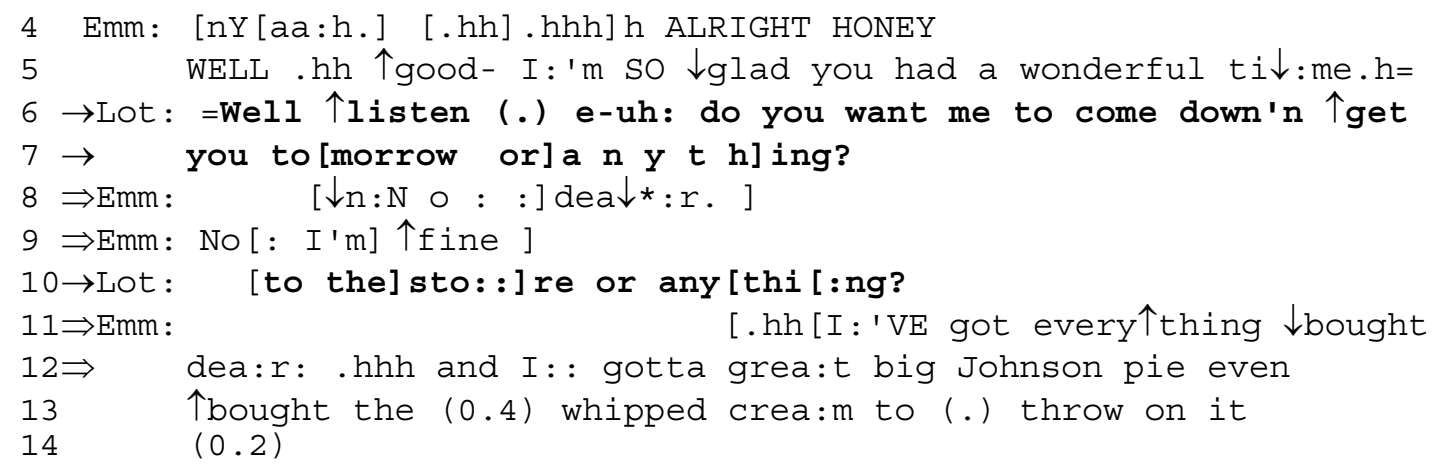

((several minutes later))

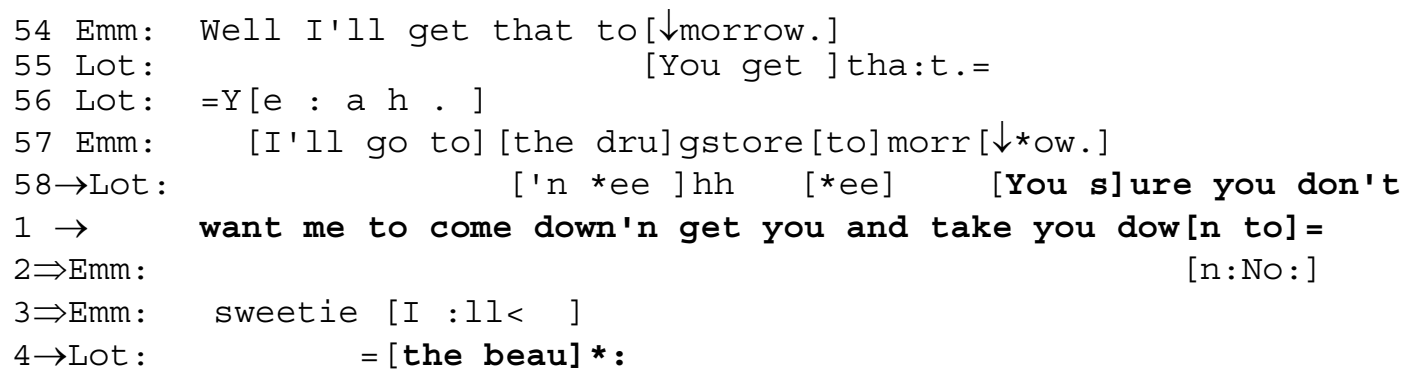

${ }^{9}$ Hyla's immediate acceptance of Nancy's Offer* in fragment (1) is in this respect an exception, but one made accountable by Nancy's having framed it as something she owes Hyla. 


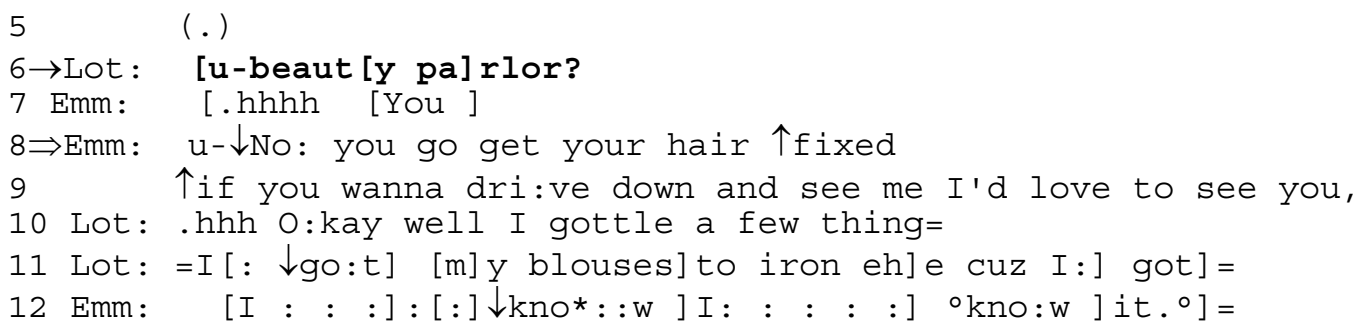

((several minutes later))

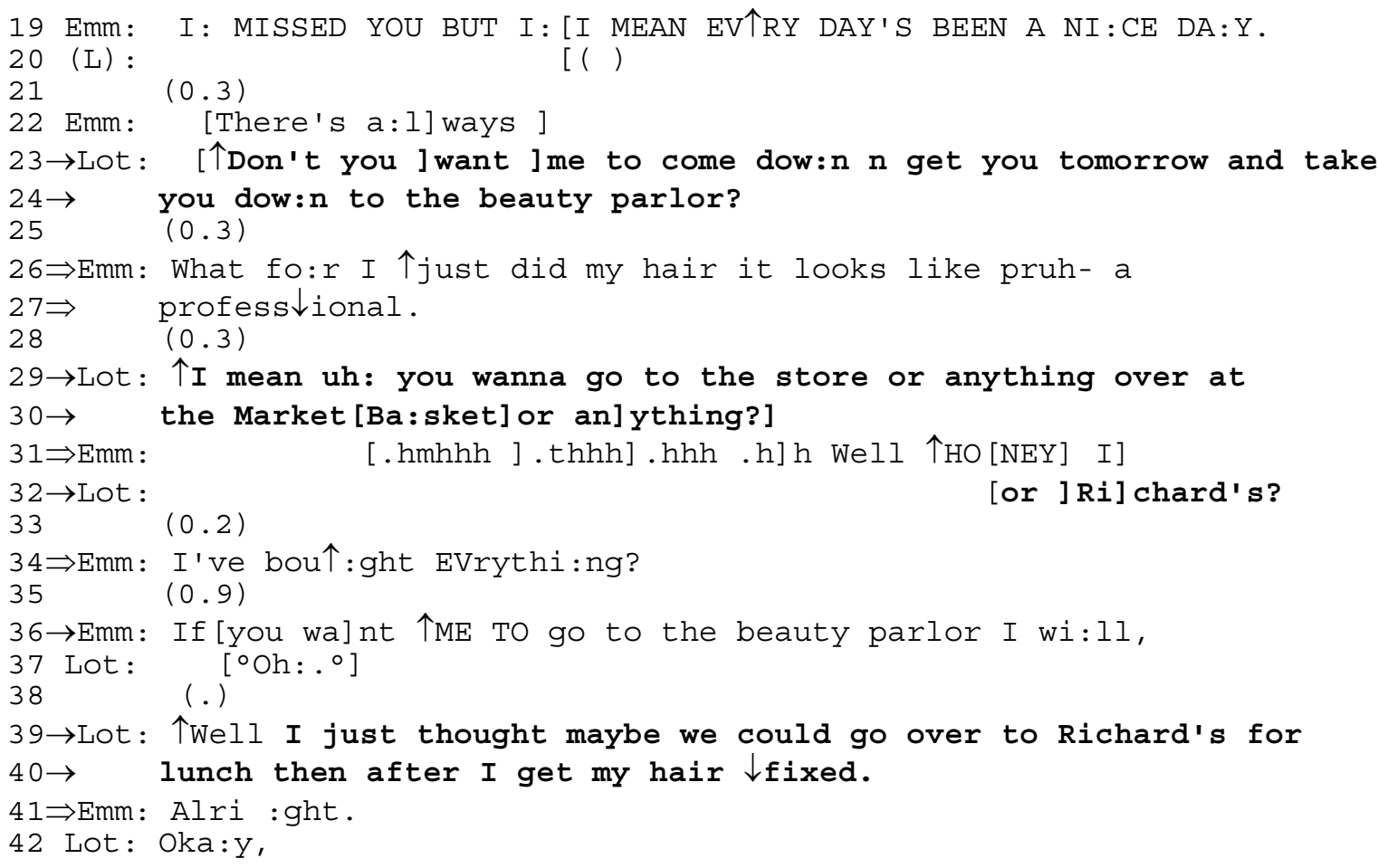

The ideas that Lottie is putting forward here (taking Emma to the store, to the beauty parlor, to the Market Basket and to Richard's) initially appear to be Offers*, i.e. activities to be performed at Lottie's cost and in Emma's interest. However, by virtue of Lottie's insisting on them despite Emma's resistance, Lottie creates the impression that the excursions may actually be in her own interest. Emma displays sensitivity to this when she responds If you want me to go to beauty parlor I will (line 36), signaling willingness to do what Lottie wants, i.e. to perform an action that will benefit Lottie but will be at Emma's 'cost' (see also Schegloff 2007: 85-6). As emerges in next turn, Lottie was actually hoping to enlist Emma as a companion for lunch at Richard's that same day (lines 39-40). Once Emma has recognized this, she agrees immediately (line $41)$.

Directive-commissive actions that frame a future action or activity as something to be performed by the recipient in the interest of the speaker are called here Requests*. They can be represented schematically as follows:

\begin{tabular}{|l|l|l|}
\hline & Agent of future action & Beneficiary of future action \\
\hline Proposal* & Self \& Other & Self \& Other \\
\hline
\end{tabular}




\begin{tabular}{|l|l|l|}
\hline Offer* & Self & Other \\
\hline Request* & Other & Self \\
\hline
\end{tabular}

Table 2. Distinctive dimensions of Proposals*, Offers* and Requests*

Requests* and Offers* are clearly related to one another: Both concern the transfer of an object or service from one participant to another (Schegloff 2007: 82) and both propose solutions to the question of who will implement the transfer and who will benefit from it. Yet they are not equivalent as actions. As Schegloff observes, Requests* are often masked as Offers* but not vice versa (2007: 84); Offers* can therefore be said to be 'preferred' (in the technical sense) over Requests* (see, however, Kendrick \& Drew (fthc.) for a different perspective on this relation). Moreover, the two types of action are treated differently by recipients. Whereas recipients prototypically decline Offers*, on the grounds that they do not need what is being offered (see fragment 6) or that it would be too much of an imposition on the offerer (see fragment 5), there is a strong social compulsion to accept Requests*. This is nicely demonstrated by the trajectory of fragment (6): As long as going to Richard's is promoted as an Offer*, i.e. as a plan to be implemented at Lottie's cost and wholly for Emma's benefit, it is declined. But as soon as it becomes apparent that going to Richard's is in Lottie's interest, then the same idea is accepted immediately. ${ }^{10}$

If Requests* are prototypically accepted readily, the acceptance of Offers* is often reluctant and may be accompanied by excuses:

(7) Chairs (sbl025-30)

[Chloe will soon be hosting a bridge party and her friend Claire has called to help with the planning. The last time Chloe hosted the bridge group, Claire brought extra chairs.]

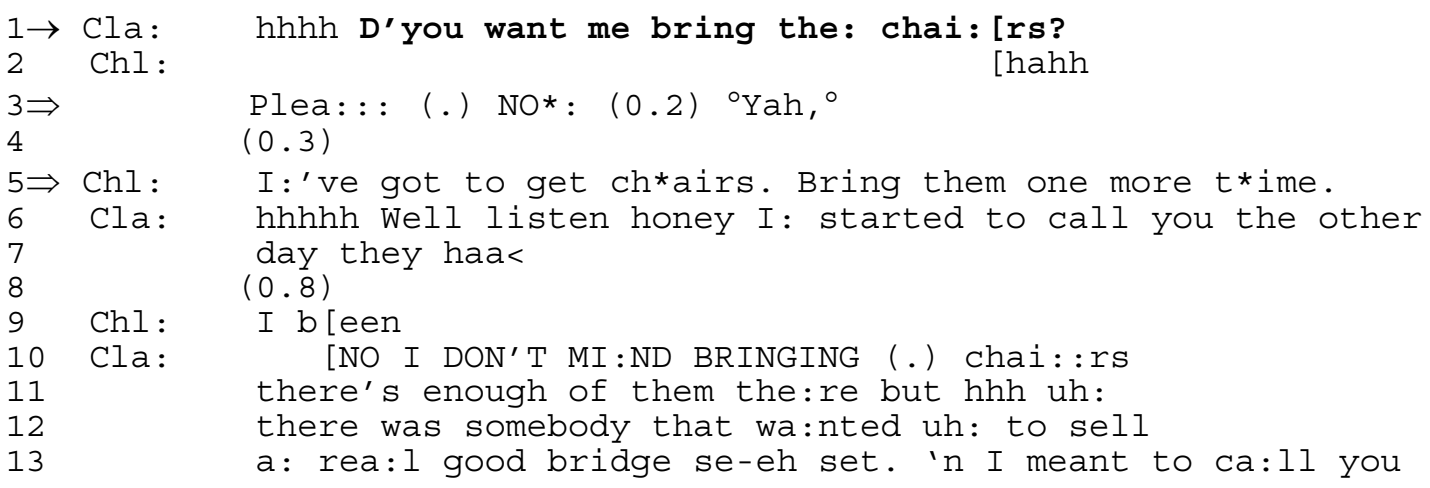

((several seconds later))

12 Chl: [hh We:ll I'll keep sorta lookin but bring them one more
13 time maybe by: next time I can get some.

Claire's turn in line 1 is hearable as an Offer* on the grounds that it advocates bringing something to the upcoming bridge party which, it is implied, Chloe needs. Bridge

10 The fact that Lottie's idea is framed as something Lottie 'wants' (line 36) and that Emma agrees to it immediately (line 41) suggests that participants are orienting to this as a Request*. Since Emma will have to wait while Lottie gets her hair fixed, the plan arguably involves costs for Emma but benefits for Lottie. 
chairs, as both know, were also lacking the last time Chloe hosted the bridge group. Chloe, however, spontaneously rejects Claire's Offer* with a loud and unmistakable NO: (line 3). But then on second thought she reverses her position and indicates that she wants to accept it after all. Significantly, her acceptance is presented as being necessitated by the fact that she lacks chairs: I've got to get chairs, and therefore wants Claire to bring some: Bring them one more time (line 5). Chloe's response to Claire's Offer* is thus framed as reluctant acceptance based on necessity. And it is accompanied by a pledge to keep looking for chairs herself and an expression of hope that she will have found some by the time of the next bridge party (lines 12-13). Thus, as a comparison of (6) and (7) shows, more interactional work is required to accept an Offer* than a Request*. This provides further evidence that participants distinguish between the two types of action.

Participants also appear to distinguish Requests*, as defined above, from an action type advocating a future action or activity to be carried out by the recipient that will benefit the recipient, to be called here Suggestion*. This is evident from what happens in the following exchange:

\section{(8) Onion dip (Kamunsky 1, p. 1-2)}

[Alan has called his friend Karen to invite her to a surprise birthday party for a mutual friend. Another friend Shawn will also be coming.]

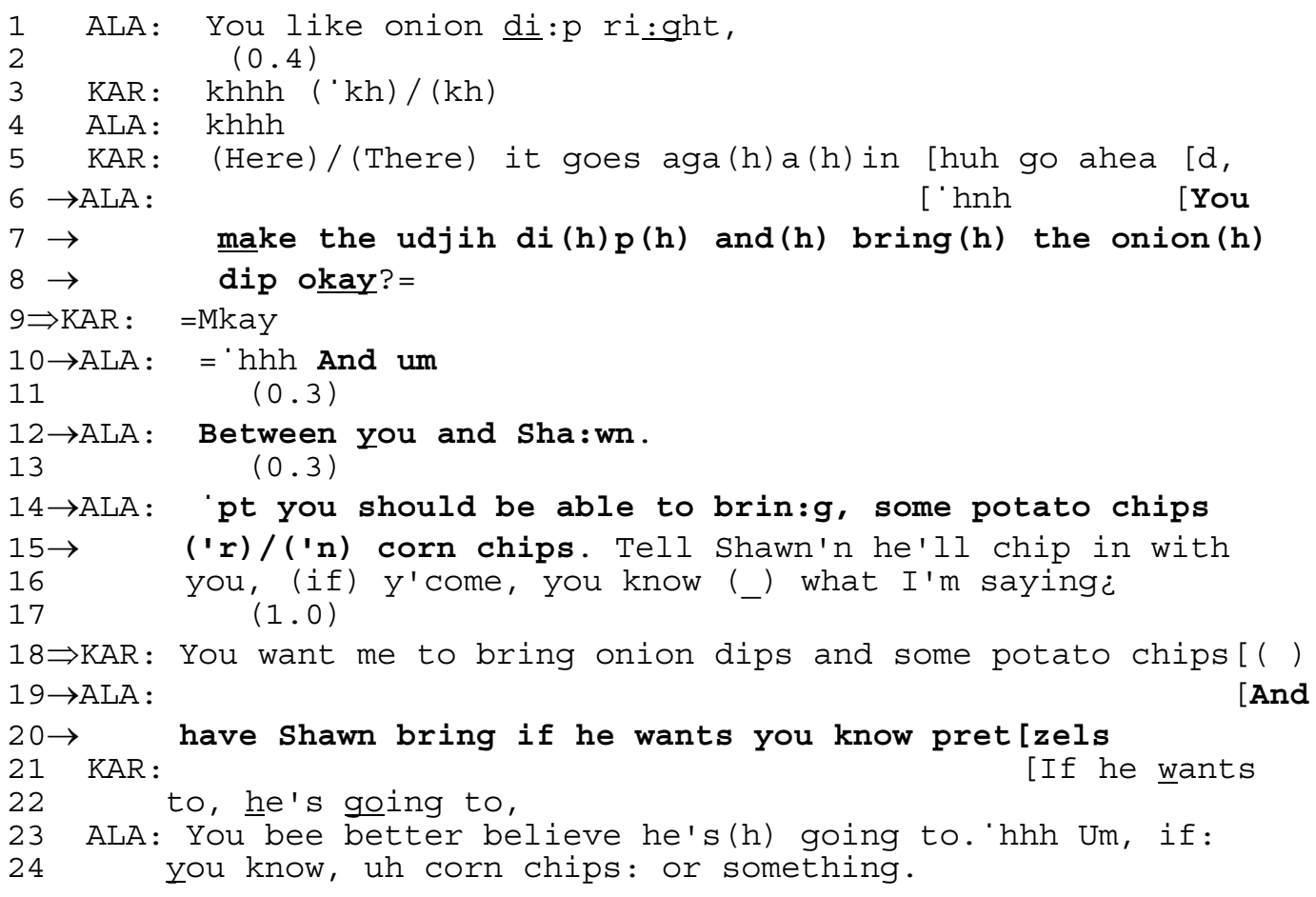

In this sequence Alan first ascertains that Karen likes onion dip (line 1 you like onion dip right) and then advances the idea that Karen make some and bring it to the party (lines 6-8). This presents Karen's bringing the onion dip as something that will be of primary benefit to her. Initiating actions that advocate future actions or activities to be carried out by the recipient that will be of primary benefit to the recipient are called Suggestions* here. They can be represented schematically as in Table 3: 


\begin{tabular}{|l|l|l|}
\hline & Agent of future action & Beneficiary of future action \\
\hline Proposal* & Self \& Other & Self \& Other \\
\hline Offer* & Self & Other \\
\hline Request* & Other & Self \\
\hline Suggestion* & Other & Other \\
\hline
\end{tabular}

Table 3. Distinctive dimensions of Proposals*, Offers*, Requests*, and Suggestions*

Interestingly, Karen makes it clear later in this sequence that she has seen through Alan's ploy. In response to his query you know what I'm saying? (line 16), she formulates the upshot of his turn as You want me to bring onion dips and some potato chips (line 18). This formulation treats Alan's plan as a Request*, something he wants her to do that will benefit him, not something she will do that will be of primary benefit to herself. It provides further evidence that although one type of directive-commissive action may be camouflaged as another, as in (8) where a Request* is masked as a Suggestion*, participants can and do distinguish between them and orient to them in recognizably different ways.

Suggestions* are like Offers* in that a future action is being promoted for the benefit of the recipient. Often they occur in sequential environments where the recipient has made some problem or trouble explicit. But they differ from Offers* in terms of who will implement the future action. With an Offer* the speaker commits to performing a future act him-/herself, while with a Suggestion* it is the participant who must act. In both cases, the speaker assumes an other-directed stance, which may explain why Suggestions*, like Offers*, are also frequently turned down. In the case of Suggestions*, the grounds for rejection are typically not that there is no need but rather that the recipient is already engaging in the action being promoted. For instance:

\section{(9) Wash them out (nb028-5)}

[In this call Emma has been telling her sister Lottie that her newly estranged husband Bud will be coming down to the beach for Thanksgiving but will leave the next day.]

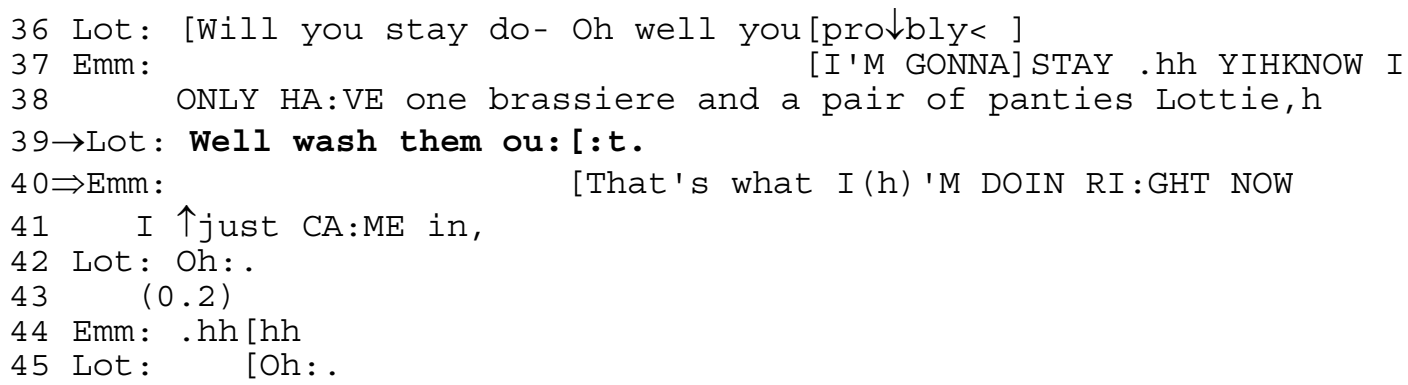

(10) Leave off the meat-1 (nb014-9)

[In this call Emma has been telling Lottie about how much better her psoriasis is after having eaten turkey at Thanksgiving.]

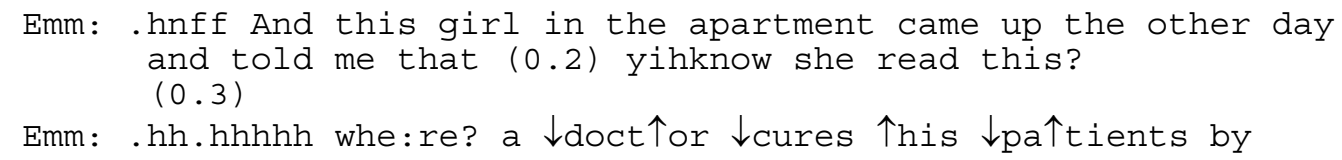




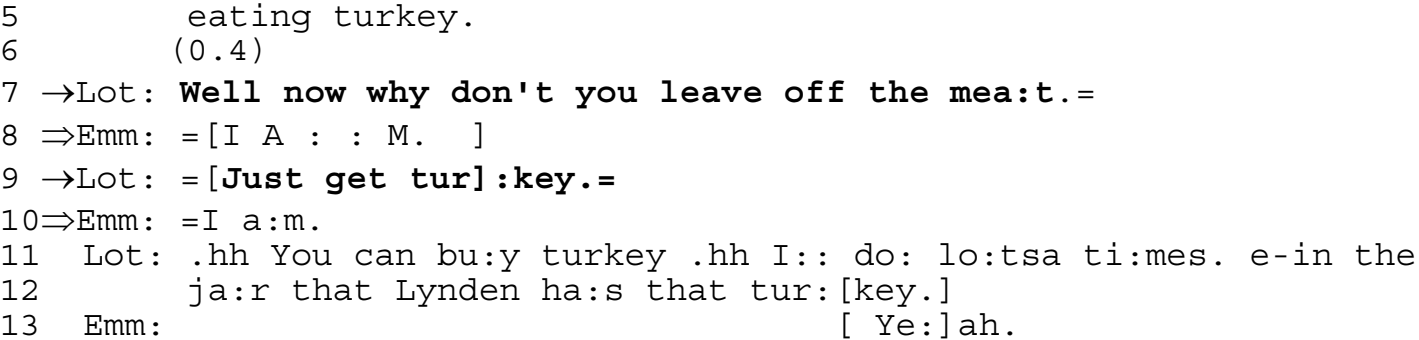

In both of these cases Emma has presented herself as having a problem (not enough fresh underwear to stay down at the beach; a painful skin condition only just beginning to improve). Lottie's reaction in each case is to advocate a simple remedy for Emma's problem: Well wash them out (line 39 of (9)) or Well now why don't you leave off the meat (line 7 of (10)). Both of these initiating turns promote future actions that Emma can undertake for her own benefit and that are presented as solutions to her problems. Yet on both occasions Emma resists the Suggestion*, the ostensible reason being that she is already engaged in the action Lottie is recommending.

In (9) and (10), it may in fact be the case contingently that Emma is already washing out her underwear or is already only eating turkey. However, the pattern that Suggestions* are likely to be resisted in everyday conversation is more widespread. Arguably, the reasons for this relate to the social order: Where problems or troubles are brought to the conversational surface, advocating a practical solution to the coparticipant's problem may be perceived as treating the talk as a problem-solving encounter rather than as an occasion for empathic affiliation (Jefferson \& Lee 1981; Heritage 2011). Speakers who propose to know immediately what action should be engaged in in order to resolve a recipient's problem place themselves in a superior position (Heritage \& Sefi 1992). In this sense recipients' resistance to Suggestions* may be a 'natural' defense to a social put-down.

To summarize the argument so far: The conversational fragments considered here have demonstrated that participants orient to a distinction between Proposals* and Offers*, as well as to one between Offers* and Requests*, and to one between Requests* and Suggestions*. In fragment (2), a plan initially presented as a Proposal* was ultimately determined to be an Offer*. In fragment (6), an idea launched as an Offer* was later unmasked as a Request*. And in example (8), an idea presented as a Suggestion* was subsequently revealed to be a Request*. The question which now arises is: How could such misapprehensions occur? Why did the recipient in (2) 'mistake' the offer for a proposal, or the recipient in (6) 'mistake' the request for an offer? How could the recipient in (8) be misled into taking a request for a suggestion? This, more generally, is the question of action ascription (Levinson 2013), to which we turn now.

\section{Linguistic forms for directive-commissive actions}

The argument to be made here is that action ascription is partially dependent on linguistic form. Participants deploy specific linguistic forms to frame their directivecommissive actions as one type or another and recipients rely on these same linguistic forms in 'recognizing' their interlocutors' actions and responding accordingly. Evidence for this claim comes from an examination of Offers*, Proposals*, Requests*, and 
Suggestions* in a moderately large database of conversational American English. ${ }^{11}$ Directive-commissive initiating turns were classified according to action type based on how they were treated in subsequent talk, i.e. on the responses they received, as well as on the agentivity roles and the allocation of costs and benefits made relevant by the participants in promoting and/or negotiating the future plan.

When Offers*, Proposals*, Requests*, and Suggestions* are examined in the database, the first thing we notice is that a number of specific lexico-syntactic patterns are recurrently used to implement them. In tabular form, showing constituent order, these patterns are as follows (see Tables 4 and 5):

\begin{tabular}{|l|l|l|l|l|l|}
\hline $\begin{array}{l}\text { Syntactic } \\
\text { category }\end{array}$ & & Subject & Auxiliary & Catenative verb & Predicate \\
\hline Indicative & & you & can/could & & $\mathrm{X}$ \\
\hline & & you & $\begin{array}{l}\text { should/ought to/ } \\
\text { have to/'d better }\end{array}$ & & $\mathrm{X}$ \\
\hline & & $\mathrm{I} / \mathrm{we}$ & will/would & & $\mathrm{X}$ \\
\hline & & $\mathrm{I} / \mathrm{we}$ & can/could & & $\mathrm{X}$ \\
\hline & & $\mathrm{I} / \mathrm{we}$ & should & & $\mathrm{X}$ \\
\hline & & $\mathrm{I} / \mathrm{we}$ & & want/wish/need & $\mathrm{X}$ \\
\hline Conditional & if & you & & want/wish/need & $\mathrm{X}$ \\
\hline
\end{tabular}

Table 4. Recurrent lexico-syntactic patterns for directive-commissive actions (Subj-Aux)

\begin{tabular}{|l|l|l|l|l|l|}
\hline $\begin{array}{l}\text { Syntactic } \\
\text { category }\end{array}$ & Auxiliary & Subject & $\begin{array}{l}\text { Catenative } \\
\text { verb }\end{array}$ & Predicate \\
\hline Imperative & & don't & $\begin{array}{l}\text { (you) } \\
\text { (you) }\end{array}$ & & $\begin{array}{l}\text { X } \\
\text { X }\end{array}$ \\
\hline $\begin{array}{l}\text { Polar } \\
\text { interrogative }\end{array}$ & & will/would & you & & $\mathrm{X}$ \\
\hline & & can/could & you & & X \\
\hline & & do & you & need/want & X \\
\hline & can/could & I/we & & X \\
\hline $\begin{array}{l}\text { Question-word } \\
\text { interrogative }\end{array}$ & why & don't & you & & X \\
\hline & why & don't & I/we & & X \\
\hline
\end{tabular}

Table 5. Recurrent lexico-syntactic patterns for directive-commissive actions (Aux-Subj)

As Tables 4 and 5 document, all of the most common English mood categories are used in implementing directive-commissive actions: Indicative, imperative, interrogative and conditional. In the interrogative category, both polar and question-word (why) forms are attested. With the exception of imperative forms, auxiliaries (especially do in the case of negation) and modal verbs (can/could, will/would, should/ought/have to/'d better) are widely represented. Subjects are exclusively first or second person. In addition, the catenative verbs need, wish and want are attested. Main verbs are invariably part of the predicate referring to the future act, represented in these tables as $X$.

11 The data stem from audiotaped telephone calls (the Newport Beach corpus and assorted other single US American calls) as well as from divers videotaped face-to-face interactions. 
Significantly, however, these grammatical forms are not freely combinable. Instead there are specific semi-fixed combinations of them recurring again and again in the materials at hand. Other possible combinations are wholly absent in the collection of directive-commissive actions. See Table 6.

\begin{tabular}{|c|c|c|}
\hline Combination & Attested & Not attested \\
\hline you can/could $X$ & $\sqrt{ }$ & \\
\hline can/could you $X$ & $\sqrt{ }$ & \\
\hline I/we can/could $X$ & $\sqrt{ }$ & \\
\hline can/could I/we X & $\sqrt{ }$ & \\
\hline you will/would $X$ & & $\sqrt{ }$ \\
\hline will/would you $X$ & $\sqrt{ }$ & \\
\hline I/we will $X$ & $\sqrt{ }$ & \\
\hline will I/we $X$ & & $\sqrt{ }$ \\
\hline you should $X$ & $\sqrt{ }$ & \\
\hline should you $X$ & & $\sqrt{ }$ \\
\hline I /we should $X$ & $\sqrt{ }$ & \\
\hline should I/we X & & $\sqrt{ }$ \\
\hline I/we need/want/wish $X$ & $\sqrt{ }$ & \\
\hline do I/we need/want/wish $X$ & & $\sqrt{ }$ \\
\hline you need/want/wish $X$ & & $\sqrt{ }$ \\
\hline do you need/want/wish $X$ & $\sqrt{ }$ & \\
\hline if you need/want $X$ & $\sqrt{ }$ & \\
\hline if I need/want $X$ & & $\sqrt{ }$ \\
\hline why do you $X$ & & $\sqrt{ }$ \\
\hline why don't you $X$ & $\sqrt{ }$ & \\
\hline why do I X & & $\sqrt{ }$ \\
\hline why don't I X & $\sqrt{ }$ & \\
\hline
\end{tabular}

Table 6. Attested and non-attested patterns for directive-commissive actions

This state of affairs strongly suggests that directive-commissive actions in conversation are not implemented by strings of morphemes that are freely combinable and permutable with one another but rather by semi-fixed patterns. In other words, the level at which the linguistic forms recurrently used for directive-commissive actions should be described is the level of construction, in the sense of Construction Grammar (Fillmore 1988; Fillmore \& Kay 1988). Yet the constructions seen in Table 6 are of a very specific type: They are used to implement social actions, social action being understood here to mean "the main job of a turn", "what the response must deal with in order to count as an adequate next turn" (Levinson 2013). For this reason, it seems appropriate to call them social action formats (Fox 2000, 2007). ${ }^{12}$

Interestingly, the social action formats collected in Table 6 are clausal in nature, and indeed - on the assumption that need/want/wish are catenative verbs monoclausal. ${ }^{13}$ This fact is noteworthy because it stands in stark contrast to the formats attested for responses to directive-commissive actions, which like other responsive actions are, more often than not, not full clauses but rather particles, phrases and/or pro-

\footnotetext{
${ }^{12}$ Of course the same constructions can also appear in other contexts and do different work.

${ }^{13}$ This does not exclude the fact that they can be incorporated into more complex syntactic frames.
} 
repeats (Thompson et al, forthcoming). One of the hallmarks of an initiating directivecommissive action is thus that it is commonly implemented by a full clausal turn. ${ }^{14}$

The next thing to observe about the formats used in directive-commissive turns is that they are distributed in patterned ways across the four different action types, Request*, Offer*, Suggestion*, and Proposal*. This can be seen from Table 7, which shows the frequencies for each format according to action type in the database. (Raw frequencies have been converted into percentages per action type; these are shown when they exceed $8 \%$.)

\begin{tabular}{|l|l|l|l|l|}
\hline Format & Request* & Offer* $^{\mathbf{1 5}}$ & Suggestion* $^{\mathbf{1 6}}$ & Proposal* \\
\hline you can/could $X$ & 1 & 1 & 4 & \\
\hline you should/ought to/have to/'d better $X$ & 2 & & $6(9 \%)$ & 1 \\
\hline I/we will $X$ & & 4 & & $9(21 \%)$ \\
\hline I would $X$ & & & $7(11 \%)$ & \\
\hline I/we can/could $X$ & & 4 & & $10(24 \%)$ \\
\hline I/we should $X$ & & & & 3 \\
\hline I/we want/wish/need $X$ & $11(13 \%)$ & 1 & & \\
\hline if you want/wish/need $X$ & 2 & $11(17 \%)$ & 4 & 2 \\
\hline if you can/could $X$ & 2 & 2 & & \\
\hline $\begin{array}{l}\text { (you ) } X \text {-IMP } \\
\text { don't (you) } X\end{array}$ & $35(40 \%)$ & $9(14 \%)$ & $24(38 \%)$ & 3 \\
\hline will/would you $X$ & $10(11 \%)$ & & $9(14 \%)$ & \\
\hline can/could you $X$ & $11(13 \%)$ & 1 & & 1 \\
\hline can/could I/we $X$ & $7(8 \%)$ & & & \\
\hline do you need/want $X$ & 3 & 3 & & 2 \\
\hline do you have $X$ & 2 & $25(38 \%)$ & & \\
\hline why don't you $X$ & 1 & & & $4(10 \%)$ \\
\hline why don't I/we $X$ & & 3 & $10(15 \%)$ & $\mathbf{4 2}$ \\
\hline Total & & 2 & & \\
\hline
\end{tabular}

Table 7. Grammatical formats for directive-commissive actions

What do we learn from these figures? First, for each action type there are multiple formats used in turn design. Yet the frequency counts suggest that each action type has favorite, or 'preferred' formats. That is, a limited set of formats is regularly used for the design of turns implementing given action types. In some cases the spread is greater than in others. Using $8 \%$ frequency as a cut-off point, there are five common formats for Request* and Suggestion*, four for Proposal* and three for Offer*. These numbers would of course be different with a higher cut-off percentage. But the point is that regardless of where the cut-off is made, specific formats are regularly associated with each action type. The preferences can be summarized as follows:

Requests* are implemented most often by imperative forms: In fact, if positive and negative imperatives are combined, more than half of all requests in the database are made with imperatives. This includes Requests* for concrete objects as, e.g., in fragments (7) and (8) above or in Give me the duck sauce, Just let me have ten dollars

\footnotetext{
${ }^{14}$ This is not to deny that the same actions can be accomplished with simple phrases and even without language at all. See also Kärkkäinen \& Keisanen (2012).

${ }^{15}$ This category includes invitations.

16 This category includes advice.
} 
please, as well as Requests* for both immediate and deferred actions: e.g., Come back in mother, Condense it down to a minute, Tell Keith Moon hello for me. One of the next most frequent Request* formats is a desiderative statement in which the speaker asserts a need, wish or desire: e.g., we need water, I want my book back, I wish you would just say something. Further frequent Request* formats, in confirmation of Curl \& Drew's (2008) findings, are queries concerning the recipient's ability or willingness to carry out a future action: Wesley would you ask the blessing please?, Will you call him tonight for me?, Could you bring out some knives?, Nance can you cut my chicken?. ${ }^{17}$

Offers* in the database are commonly implemented by one of three linguistic formats. The most frequent of these is a polar interrogative querying the recipient's need or desire for some future act as, e.g., in fragments (6) and (7) above or in Do you need any silver? or (Do) you want me to cancel it?. ${ }^{18}$ Next most frequent is a format in which the recipient's possible need or desire for the future act is expressed conditionally: e.g., if you guys want a place to stay or my table's still set up if you want to play bridge this afternoon. These findings corroborate Curl's (2006) observations for offers of assistance in English conversation. ${ }^{19}$ The third most frequent format for Offers* as conceptualized here, i.e. including invitations, is a positive imperative: e.g., You eat it now or Come on down here (I've got beer and stuff).

Suggestions*, a category that includes advice-giving, are implemented by one of five different formats in the database. Well over half of all Suggestion* turns are formatted either as positive imperatives or as negative ones (prohibitives): e.g., line 39 of fragment (9); line 9 of fragment (10) or You keep your nose clean, Don't be up there alone. The next most frequent Suggestion* format is a negative why question: e.g., line 7 of fragment (10); why don't you get that Revlon Nail or why don't you try taking it again. Also relatively common is a Suggestion* format in which the speaker formulates hypothetically what future action they would or would not take if they were in the recipient's position: e.g., I'd do it professionally wouldn't you?, I'd just go ahead and do it on your own, I wouldn't call Barbara. A further Suggestion* format found relatively frequently is a deontic assertion of what the recipient should do in the future: e.g. You ought to stay down, Maybe you should make a few phone calls. With the possible exception of the $I$ would $X$ format, Suggestion* formats always incorporate an explicit or implicit reference to you (i.e., the recipient).

Proposals* for joint action in the database are distributed over four recurrent turn formats, the most common of which involves a statement of ability about what the speaker and recipient might do together, e.g. lines $9 \mathrm{f}$ in fragment (3); lines $10 \mathrm{f}$ in fragment (4); lines 39f in fragment (6) or I thought maybe we could have dinner, maybe we can have a last minute poker game or something. Related to this is another Proposal* turn design in which the speaker advances the joint action with a negative why question: e.g., Why don't we all do that, Why couldn't we have them come at seven o'clock instead of eight (see also Drew 2013). Whereas these two formats regularly incorporate the mention of an inclusive we, other typical Proposal* turn designs formulate a division of labor with the recipient being assigned one part of the job and the speaker pledging to do the other or vice versa: e.g. why don't you call me tomorrow

\footnotetext{
${ }^{17}$ In speech act theory, these forms might be said to question one of the felicity conditions for a given speech act and in doing so, to implement that action indirectly (Searle 1975; Levinson fthc.).

18 These forms too might be said to question a felicity condition in speech act theory.

19 The format I'll $X$ was less frequent, relatively speaking, comprising only $6 \%$ of the Offer* turns in the database.
} 
morning and I'll call him tonight or why don't I bring it home with me and you can drop by my house and get it (Couper-Kuhlen \& Etelämäki, fthc). In these cases, the reference to a joint 'we' is implicit.

A third and final observation to make based on Table 7 is that there is surprisingly little overlap between the preferred formats for different action types. It is true that, for instance, you should $X$ can be used to implement a Request*, a Suggestion*, and a Proposal*, but in fact it is a frequent format (defined here with a cutoff point of $8 \%$ for the category in question) only for Suggestions*. The same applies to do you want/need $X$ : It can be used to implement Requests*, Offers*, and Proposals* but is only frequent for Offers*. Table 8 presents an overview of the frequent formats that are associated with only one action type:

\begin{tabular}{|l|l|l|l|l|}
\hline Format & Request* & Offer* & Suggestion* & Proposal* \\
\hline you should $X$ & & & $\sqrt{ }$ & \\
\hline I will $X$ & & & & $\sqrt{ }$ \\
\hline I would $X$ & & & $\sqrt{ }$ & \\
\hline I/we can/could $X$ & & & & \\
\hline $\begin{array}{l}\text { I/we } \\
\text { want/wish/need } X\end{array}$ & $\sqrt{ }$ & & & \\
\hline $\begin{array}{l}\text { if you } \\
\text { want/wish/need } X\end{array}$ & & $\sqrt{ }$ & & \\
\hline will/would you $X$ & $\sqrt{ }$ & & & \\
\hline can/could you $X$ & $\sqrt{ }$ & & & \\
\hline $\begin{array}{l}\text { do you need/want } \\
X\end{array}$ & & $\sqrt{ }$ & & $\sqrt{ }$ \\
\hline why don't I/we $X$ & & & & \\
\hline
\end{tabular}

Table 8. Distinctive frequent formats for directive-commissive actions

Table 9 presents those frequent formats that are associated with more than one action type:

\begin{tabular}{|l|l|l|l|l|}
\hline Format & Request* & Offer* & Suggestion* & Proposal* \\
\hline (you) $X$-IMP & $\sqrt{ }$ & $\sqrt{ }$ & $\sqrt{ }$ & \\
\hline don't (you) $X$ & $\sqrt{ }$ & & $\sqrt{ }$ & \\
\hline why don't you $X$ & & & $\sqrt{ }$ & $\sqrt{ }$ \\
\hline
\end{tabular}

Table 9. Overlapping frequent formats for directive-commissive actions

Judging from Table 9, positive imperatives are the most 'polysemous' of the recurrent formats: They are commonly used to implement three different directive-commissive action types. Negative imperatives are, however, already less so: They frequently implement only two different directive-commissive action types. For the other frequent formats, there are also only two readings each.

What these findings suggest is that the frequency relations holding between linguistic format and directive-commissive action type provide important cues for action ascription. It is perhaps not irrelevant that the crucial aspects of the formats identified here - subjecthood (you or me as agent?), interrogativity (are you asking me or telling me?), conditionality (is this a hypothetical or not?), modality (ability, willingness or necessity?) and imperativity (is non-compliance an option or not?) - all 
make themselves apparent, at least in English, at the outset of the turn. The reference to what act is being advanced ( $X$ in our tables) comes later. This means that such linguistic formats satisfy a sine qua non for action ascription: Through their early positioning they allow time for the recipient to plan a proper responsive action (Levinson 2013) and to do so in a way that is sensitive to action type.

Importantly, the claim being made here is not that recipients rely solely on linguistic format for action ascription. Of course there are other grounds on which they can and do form interpretive hypotheses. For instance, how the future action or plan is construed lexically: A verb such as get together clearly favors a joint-action or Proposal* reading. Or, what conditions hold otherwise: Volunteering to take someone to a restaurant if one does not drive favors an Offer* interpretation. And more generally, how talk has developed so far: Referring to a future action the recipient should perform in the context of troubles talk is likely to be a Suggestion*. All these considerations make an important contribution to action ascription. Yet because of the relatively straightforward frequency relation between linguistic form and action type, the choice of one particular linguistic format over another also provides important input.

\section{Linguistic formats and response realignment and misalignment}

Returning now to the fragments above in which participants were misaligned concerning action type or in which recipients realigned their response according to a different action type, we can often trace the misalignment and/or realignment to the specific linguistic formats used in the implementation of the directive-commissive actions.

\section{(1) Buy you a drink}

1 Hyla: .hh Maybe we can go out for a drink tonight.

$$
\text { . }
$$

5 Nancy: I wanna buy you a dri:n[k

The we can $X$ format is commonly used for a Proposal* (see Table 7). That is, it is hearable as advocating an activity that the initiator and recipient will engage in jointly and with respect to which they will share both the costs and the rewards. The recipient's initial response That soun(ds good/like fun) indeed treats line 1 as a Proposal* by launching a (positive) evaluation of it next (Stevanovic 2012). Had it been pursued to completion, the positive evaluation would have implied that the recipient was 'buying into' the terms of the Proposal*, namely agreeing to share the costs. This implication is what Nancy is concerned to avert when she now realigns her response to I owe you a drink (.) I wanna buy you a drink (lines 3 and 5). Her repaired response formulates an Offer* instead: It advocates a future action that the speaker (Nancy) will carry out and that will be of primary benefit to the addressee (Hyla). Note that this turn design might appear to be an instantiation of the $I$ wish/want/need $X$ format but is not interpretable as implementing a Request*, because it is the speaker who is construed as the agent of the future act. When used for Requests*, the $I$ wish/want/need $X$ format invariably 
construes the recipient as future agent: I wish you would just say something or I want some of that Mommy.

\section{(2) Coco's-2}

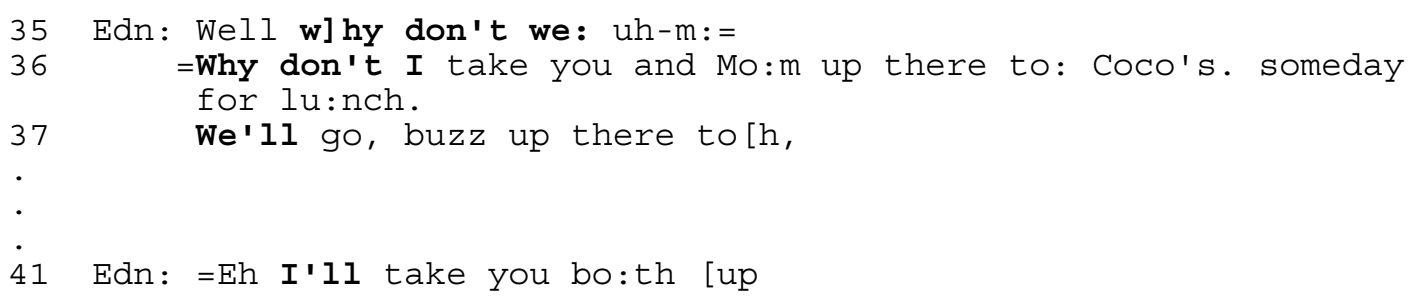

Starting in line 35, Edna launches her turn with a why don't we $X$ format but then selfrepairs this to why don't I $X$ (line 36). This suggests that she is concerned to avoid being heard as implementing a Proposal*, which would imply sharing the costs jointly. Instead, the format she opts for, why don't I $X$, because it lacks a 'you' counterpart advancing a bilateral action, presents the idea as an Offer*, one whose costs will accrue to the speaker. Yet in her turn continuation, Edna deploys a we will $X$ format, suggestive of a Proposal* reading (Table 7). It is perhaps for this reason that Margy orients to the turn as advocating a joint plan that requires evaluation, i.e. as a Proposal*. Based on the immediacy of her positive response good/that's a good deal, Margy's understanding at this point is arguably that they will share the costs. However, when Edna now says I'Il take you both up (line 41), she can be heard to be 'clarifying' her initiative as actually being an Offer*, implying that she will assume the costs. This is indicated by her choice of the $I$ will $X$ format (Table 7). Margy's adamant rejection in next turn shows that she has also interpreted it this way.

\section{(3) Greyhound bus}

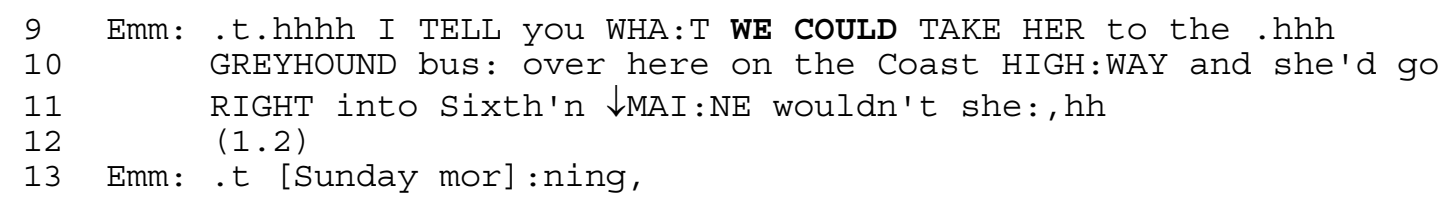

Emma chooses a format that is common for a Proposal*, we could $X$ (see Table 7). An Offer* understanding is implausible here, given the fact that Emma does not drive and her husband Bud is not available. With its preface I tell you what, Emma's idea is presented as a suddenly devised, ingenious solution to a problem. Yet it is unclear who the we in line 9 refers to. Lottie's initial response does not take up the Proposal* elements of Emma's turn: She does not evaluate it positively but with yeah merely acknowledges that what Emma is advancing is indeed a possible plan. It is not until Emma pursues and solicits more adequate uptake that Lottie's responses finally deal with the deontic implications of Emma's turn. In fact, since Emma does not drive herself, the joint action being advocated actually implies that Lottie will do the driving. Lottie's responses display that she has now understood this agenda: She agrees to the plan (sure) and positively evaluates it in a way that attests to her willingness to carry it out (that's easy).

\section{(6) Beauty parlor}




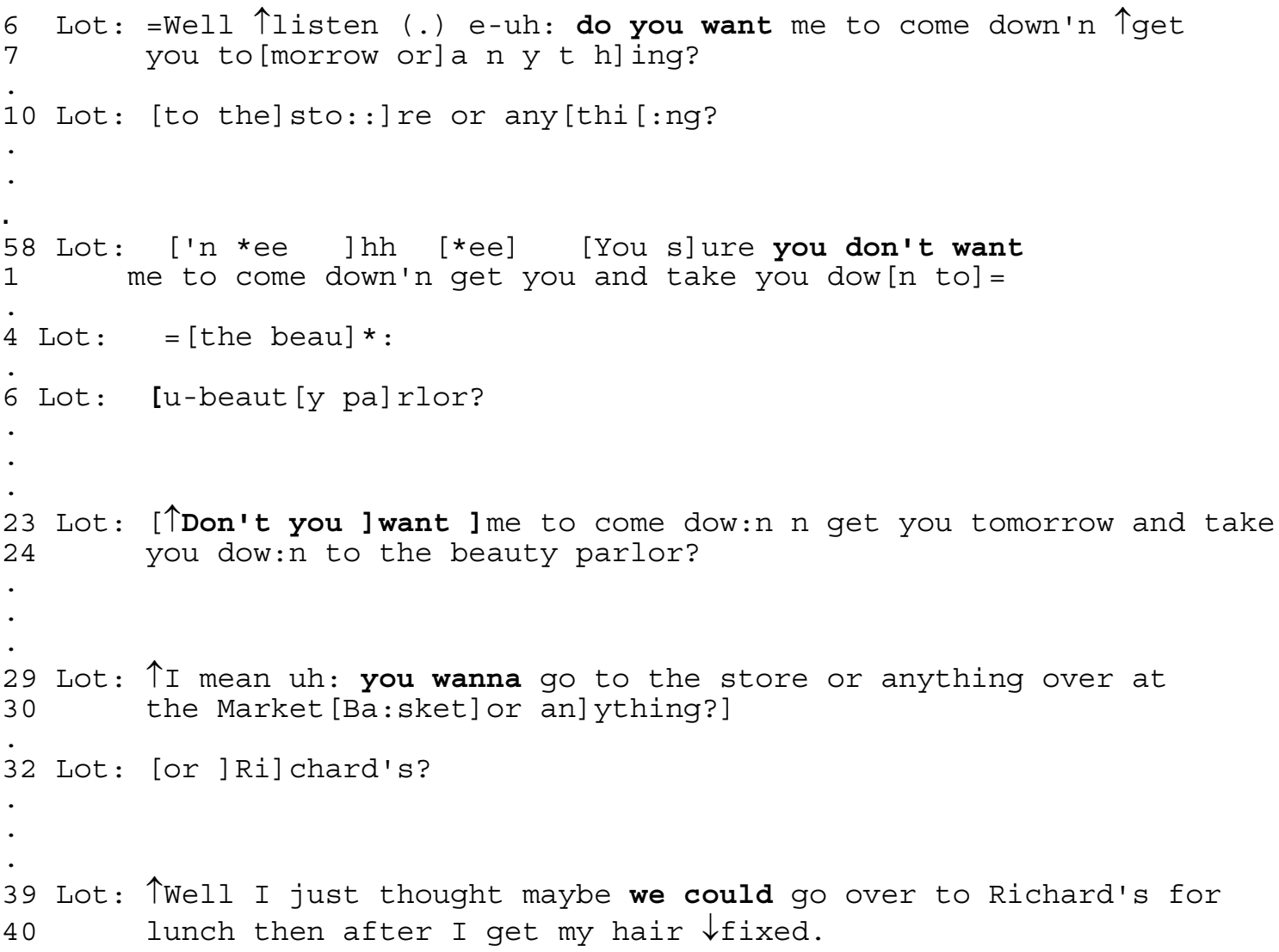

Lottie initially chooses a do you want $X$ format (line 6), which in the given context (Emma's recent estrangement from her husband and Lottie's absence over the weekend) is interpretable as an Offer* (see Table 7). A Request* reading is unlikely because it is the speaker who is construed as future agent, not the recipient. A Proposal* reading is excluded because there is no corresponding component setting out the recipient's part in the activity: The outing is construed unilaterally. Emma's subsequent demurral is consistent with an Offer* interpretation. Lottie's next two attempts (lines 58ff and 23ff) also use do you want $X$ formats but ones whose negative form acknowledges Emma's prior rejection. Lottie's third attempt (lines 29ff) is done as a revised version of lines $23 \mathrm{ff}$, following another rejection from Emma, with I mean (do) you want $X$. All of these initiating turns are interpretable in context as Offers* and Emma indicates that she understands them as such by demurring. However, once Lottie's insistence on offering has been unmasked as wanting something for herself, she reformulates her plan with a we could $X$ format (line 39). This makes the idea hearable as a Proposal* (Table 7), one that would involve shared costs and benefits. However, Emma treats it as an implicit Request* by signaling immediate compliance (rather than, say, evaluating its merits as a course of joint action).

\section{(8) Onion dip}

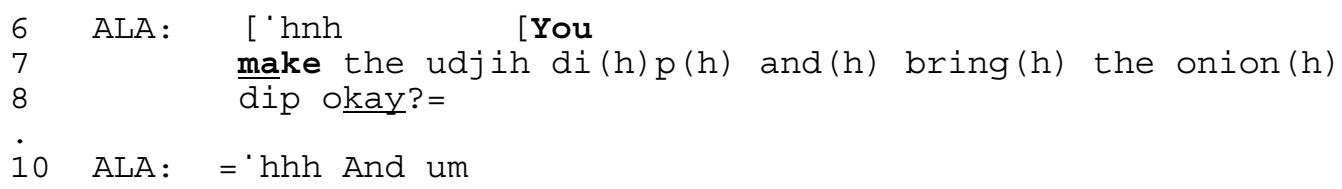




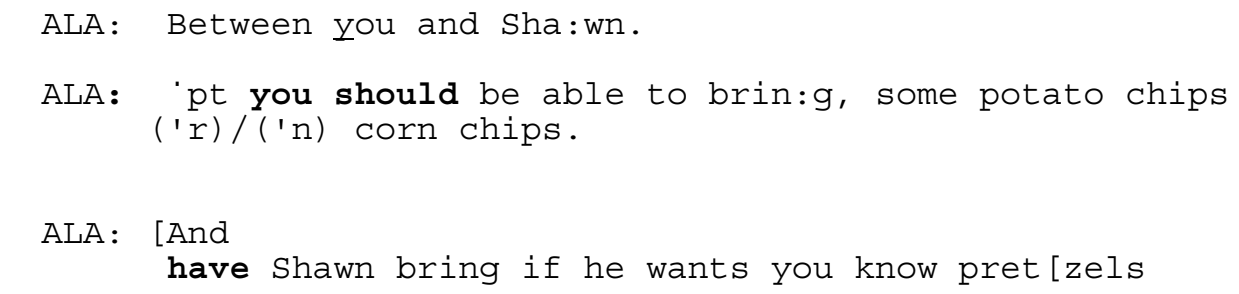

The imperative forms in lines 6-8, accompanied by 'you', instantiate the format IMP $X$. As Table 7 attests, this format can be used for all four of the directive-commissive actions under consideration here. Yet in context, because they build on a pre-sequence that has established the potential benefit of onion dip for Karen, lines 6-8 are compatible with a Suggestion* reading. ${ }^{20}$ A Proposal* reading of this line is excluded because there is no corresponding commitment by the speaker for bilateral engagement in the activity. Alan's next initiative (lines 10ff) is, however, more ambivalent. On the one hand, its format you should $X$ could convey a Suggestion* (see Table 7); however, 'be able to' would be hard to make sense of on this reading. Moreover, Karen has not made a problem or trouble relevant nor is there is any evidence that she will be the primary beneficiary of bringing potato chips. In fact, it is implied that she will have to bear the costs, which she can reduce by enlisting Shawn's help. Thus, Karen's candidate understanding of these lines (and retrospectively of the prior ones) as implementing a Request* is well motivated. Alan implicitly ratifies the Request* understanding in lines 19f by continuing with another future act that Karen is to carry out and that stands to benefit him and his party.

To summarize, this section has shown that misalignments and realignments concerning action type can be traced, among other things, to the linguistic formats the initiating speakers use. On occasion, the formats chosen are contradictory and lead to misalignment - as, e.g., in fragment (2) with Edna's why don't we $X$ (Proposal*), why don't $I X$ (Offer*), and we'll $X$ (Proposal*). On other occasions, speakers may intentionally cover their tracks by choosing other-directed formats for what are actually self-serving motives - as, e.g., in (6) where the plan in question is presented as an Offer* but turns out to be a Request* (under the guise of a Proposal*), or in (8) where an idea is construed as a Suggestion* but is actually a Request*. The fact that some formats can have multiple readings, e.g. do you want $X$ or IMP $X$, facilitates this kind of 'deviousness'.

\section{Conclusion}

The argument made here has been that standard linguistic formats - recurrent ways of implementing directive-commissive actions - provide cues for action ascription in interaction. The fact that there is only a limited amount of overlap in the formats commonly used for Proposals*, Requests*, Offers*, and Suggestions* in English conversation means that these forms deliver often distinctive cues to the directivecommissive action being implemented. Where there is overlap in commonly used

${ }^{20}$ The Suggestion* reading may be encouraged by the presence of 'you' along with the imperative form. Compare lines 19-20 where 'you' is lacking and the turn is more unambiguously a Request*. The interactive role of 'you' in imperatives is an issue requiring more empirical research. 
formats, e.g. imperatives for both Requests* and Suggestions*, the ambivalence can become a source of possible misapprehension. Formal overlaps are of course also open to exploitation and thus allow for strategic manipulation.

The notion of social action format, originally introduced to describe recurrent linguistic forms for assessing in conversation (Goodwin \& Goodwin 1992; Fox 2000, 2007), has also proved to be relevant here for describing frequent ways of requesting, offering, proposing, and suggesting. This implies that the concept may be more generally applicable and indeed a productive way of thinking about the implementation of action in talk-in-interaction. The social action formats identified in this study are in many ways like the constructions of Construction Grammar $(\mathrm{CxG})$. However, social action formats are used for specific kinds of social action in interaction. Moreover, social action formats are multimodal: They can embrace both linguistic and embodied forms, as work by Kärkkäinen \& Keisanen (2012) and Rauniomaa \& Keisanen (2012) shows. Thus, the notion of social action format appears to offer a particularly appropriate conceptual framework for describing semi-conventionalized ways of implementing action in social interaction.

In conclusion, pace Schegloff (1984), grammar does tell us something about social action. It provides a basis on which recipients form working hypotheses about what action a co-participant is initiating. And it does this relatively early in the turn, thus enabling recipients (i) to determine an appropriate responsive action and (ii) to implement it in a timely fashion. This is not to deny that lexical choices as well as the sequential position of a turn, its location within a larger project and ongoing activity, as well as a host of other situational factors are also relevant for action ascription. The point is that the contribution of grammar, in the sense of social action formats, is not negligible.

\section{References}

Atkinson, J.M., and J. Heritage (eds.) (1984) Structures of Social Action: Studies in conversation analysis. Cambridge: Cambridge University Press.

Austin, J.L. (1962) How to Do Things with Words. London: Oxford University Press.

Couper-Kuhlen, E., and M. Etelämäki (fthc.) On divisions of labor in request and offer environments. In Paul Drew, and E. Couper-Kuhlen (eds.), Requesting in Social Interaction. Amsterdam: John Benjamins Publishing Company.

Curl, T.S. (2006) Offers of assistance: Constraints on syntactic design. Journal of Pragmatics 38: 12571280 .

Curl, T.S., and P. Drew (2008) Contingency and action: A comparison of two forms of requesting. Research on Language and Social Interaction 41.2: 129-153.

Drew, P. (2013) Conversation analysis and social action. Journal of Foreign Languages 37.3: 1-20.

Ervin-Tripp, S. (1976) "Is Sybil there?" The structure of some American English directives. Language in Society 5.1: 25-66. 
Fillmore, C.J. (1988) The mechanisms of "construction grammar". Proceedings, Berkeley Linguistics Society 14: 35-55.

Fillmore, C.J., P. Kay, and M-C. O'Connor (1988) Regularity and idiomaticity in grammatical constructions: The case of LET ALONE. Language 64.3: 501-538.

Fox, B.A. (2000) Micro-syntax in English conversation. Paper presented at the conference Interactional Linguistics (sponsored by EURESCO), September, Spa, Belgium.

Fox, B.A. (2007) Principles shaping grammatical practices: An exploration. Discourse Studies 9: 299318.

Goodwin, C., and M.H. Goodwin (1992) Assessment and the construction of context. In A. Duranti, and C. Goodwin (eds.), Rethinking Context. Language as an interactive phenomenon. Cambridge: Cambridge University Press, pp. 147-189.

Heritage, J. (2011) Territories of knowledge, territories of experience: Empathic moments in interaction. In T. Stivers, L. Mondada, and J. Steensig (eds.), The Morality of Knowledge in Conversation. Cambridge: Cambridge University Press, pp. 159-183.

Heritage, J., and S. Sefi (1992) Dilemmas of advice: Aspects of the delivery and reception of advice in interactions between health visitors and first-time mothers. In P. Drew, and J. Heritage (eds.), Talk at Work. Interaction in institutional settings. Cambridge: Cambridge University Press, pp. 359-417.

Jefferson, G., and J.R.E. Lee (1981) The rejection of advice: Managing the problematic convergence of a "troubles-telling" and a "service encounter". Journal of Pragmatics 5: 399 - 422.

Kärkkäinen, E., and T. Keisanen (2012) Linguistic and embodied formats for making (concrete) offers. Discourse Studies 14.5: 587-611.

Kendrick, K.H., and P. Drew (fthc.) The putative preference for offers over requests. In P. Drew, and E. Couper-Kuhlen (eds.), Requesting in Social Interaction. Amsterdam: John Benjamins Publishing Company.

Levinson, S.C. (1983) Pragmatics. Cambridge: Cambridge University Press.

Levinson, S.C. (2013) Action formation and ascription. In J. Sidnell, and T. Stivers (eds.), The Handbook of Conversation Analysis. Malden MA: Wiley Blackwell, pp. 103-130.

Levinson, S.C. (fthc.) Speech acts. In Y. Hwang (ed.), The Oxford Handbook of Pragmatics. Oxford: Oxford University Press.

Lindström, A. (fthc.) Accepting remote proposals. In G. Raymond, G.H. Lerner, and J. Heritage (eds.), Enabling human conduct: Naturalistic studies of talk-in-interaction in honor of Emanuel A. Schegloff. Amsterdam: John Benjamins Publishing Company.

Rauniomaa, M., and T. Keisanen (2012) Two multimodal formats for responding to requests. Journal of Pragmatics 44: 829-842.

Schegloff, E.A. (1980) Preliminaries to preliminaries: "Can I ask you a question?". Sociological Inquiry 50: $104-152$.

Schegloff, E.A. (1984) On some questions and ambiguities in conversations. In J.M. Atkinson, and J. Heritage (eds.), Structures of Social Action: Studies in conversation analysis. Cambridge: Cambridge University Press, pp. 28-52.

Schegloff, E.A. (2007) Sequence Organization in Interaction: A Primer in Conversation Analysis, Vol. 1. Cambridge: Cambridge University Press. 
Searle, J.R. (1969) Speech Acts: An essay in the philosophy of language. Cambridge: Cambridge University Press.

Searle, J.R. (1975) Indirect speech acts. Syntax and Semantics, Vol. 3: Speech acts. P. Cole, and J.L. Morgan (eds.). New York: Academic Press, pp. 59-82.

Searle, J.R. (1976) A classification of illocutionary acts. Language in Society 5: 1-23.

Stevanovic, M. (2012) Prosodic salience and the emergence of new decisions: On approving responses to proposals in Finnish workplace interaction. Journal of Pragmatics 44: 843-862.

Stevanovic, M., and A. Peräkylä (2012) Deontic authority in interaction: The right to announce, propose, and decide. Research on Language and Social Interaction 45: 297-321.

Thompson, S.A., B.A. Fox, and E. Couper-Kuhlen (fthc) Grammar and Everyday Talk: Building responsive actions. Cambridge: Cambridge University Press.

ELIZABETH COUPER-KUHLEN was Finland Distinguished Professor for Interactional Linguistics at the University of Helsinki from 2009-2013. Before this appointment she held professorships in English Linguistics at the University of Konstanz and the University of Potsdam in Germany. Her interests lie in the study of language in interaction. She is the author of An Introduction to English Prosody and English Speech Rhythm; co-author (with Peter Auer and Frank Müller) of Language in Time; and co-editor of Prosody in Conversation (with Margret Selting), Studies in Interactional Linguistics (with Margret Selting) and Sound Patterns in Interaction (with Cecilia E. Ford).

Address: Faculty of Arts, University of Helsinki, 00014 Helsinki, Finland. E-mail: Elizabeth.couperkuhlen@helsinki.fi 